\title{
Phylogenic Relationship of Salmonella Serovars Isolated from Different Foodstuffs in Isfahan
}

Original Article

Somaieh Sabzali it

(PhD Candidate) Department of Cell

and Molecular Biology \&

Microbiology, Faculty of Biological

Science and Technology, University of

Isfahan, Isfahan, Iran

Majid Bouzari

(PhD) Department of Cell and

Molecular Biology \& Microbiology,

Faculty of Biological Science and

Technology, University of Isfahan, Isfahan, Iran

Corresponding author: Majid bouzari Email: bouzari@sci.ui.ac.ir

Tel: +983137932459

Address: Department of Biology,

Faculty of Sciences, University of

Isfahan, Isfahan, Iran

Received: $2019 / 12 / 16$

Revised: 2020/01/26

Accepted: 2020/02/1

\section{(c) (i) (8)}

This work is licensed under a $\underline{\text { Creative }}$ Commons Attribution 4.0 License.

DOI:10.29252/mlj.14.4.20

\begin{abstract}
Background and objectives: are divided into two species: Salmonella enterica and Salmonella Salmonella bongori. S. enterica has more than 2,500 serotypes. Serovars of S. enterica such as Typhimurium, Enteritidis, Paratyphi B, Paratyphi A and Newport are associated with human infections. Approximately $75 \%$ of human Salmonella infections have been associated with contaminated food such as eggs, chicken, beef, pork, dairy products, fruits and vegetables. The aim of this study was to determine the frequency of Salmonella strains isolated from various food sources in Isfahan, Iran.
\end{abstract}

Methods: Forty Salmonella strains were isolated from 450 suspected cases referred to the veterinary reference laboratory of Isfahan Province. The isolates were identified by differential and serotyping tests and then confirmed by PCR. A phylogenic tree was constructed with 34 sequences by neighbor-joining method using the MEGA7 software (version 7.1).

Results: Overall, 10 Salmonella serovars were isolated from 32 chicken meat, three beef and five egg shell samples. S. enterica serovar Ouakum $(20 \%)$, S. Enteritidis $(17.5 \%)$ and S. Typhimurium (17.5\%) were the most common serovars, while S. enterica serovar Nitra $(2.5 \%)$ was found as the least prevalent isolate.

Conclusion: In this study, S. Typhimurium species is placed in different clusters along with sequences reported from different parts of the world, indicating that the serovars are circulating all over the world.

Keywords: Salmonella enterica, Phylogenic tree, MEGA7 Software. 


\section{INTRODUCTION}

Foodborne diseases are one of the most important health problems in the world, which are associated with a substantial economic and health burden (1). An important issue in food production is the growth of production proportional to supply and demand, and this supply must be hygienic and of high quality.

Food contamination can be caused by several agents including presence of bacteria and their byproducts in raw food materials or food products, which leads to culling. The presence of pathogenic bacteria such as Salmonella, Escherichia coli, Campylobacter, Yersinia, Vibrio, etc. in food products can have devastating effects on the health and economy of countries, which can be largely prevented by continuous surveillance (2). Salmonellosis is a zoonotic disease and one of the most common foodborne infections in the world. Each year, more than 1.4 million cases of non-typhoid Salmonella infection are reported worldwide (3). In the European Union, 52.3\% and $23.3 \%$ of all salmonellosis cases are caused by Salmonella enterica serovar Enteritidis and Salmonella enterica serovar Typhimurium, respectively. $S$. enterica serovar Infantis has been also reported from Europe. According to the European Food Safety Authority, the overall economic burden of these infections in humans could be as high as 3 billion Euros per year (4). The clinical symptoms of human salmonellosis include subclinical gastroenteritis, severe bacteremia, fever, meningitis and other forms of extraintestinal infections (5). Classification of Salmonella species is difficult due to its high diversity. Today, more than 2,500 Salmonella serotypes have been identified that are categorized into groups A, B, C and D based on their virulence factors (6-8) . S. typhimurium, $S$. enterica serovar Newport, $S$. enterica serovar Heidelberg and S. enterica serovar Javiana are associated with human infections in the US (9). S. enterica serovar Typhi is capable of surviving in harsh conditions and the human digestive tract. Biofilms formed by Salmonella in gallbladder can lead to chronic symptomless infection (typhoid carriers), which can evade the immune system. These bacteria can survive in cold environment (refrigerators) but are sensitive to dryness, heat and disinfectants (10). Food associated to salmonellosis includes chicken meat, pork, beef, eggs, dairy products, seafood, parsley, coriander, broccoli, cauliflower, lettuce, spinach, etc. Contact with contaminated surfaces such as furniture, appliances and equipments is the main cause of cross contamination of chicken meat, beef and pork. Contamination in pre-prepared products made from meat and vegetables can also pose as a health threat (9). $S$. Enteritidis and $S$. Typhimurium that are considered as the main causes of human infections are commonly isolated from poultry, which is a major potential vehicle of Salmonella enterica serovar Kentucky ST198 clone. Therefore, presence of any new zoonotic serovar of Salmonella in poultry should be considered as a local and global public health threat (11).

This study aimed to determine of the frequency of Salmonella serovars from different sources and also to determine the phylogenetic correlation of these serovars referred to the veterinary reference laboratory of Isfahan Province, Iran.

\section{MATERIALS AND METHODS}

From June 2016 to June 2017, a total of 40 Salmonella strains were isolated from 450 suspected Salmonella spp. cases that were referred to the veterinary reference laboratory of Isfahan Province, Iran. Swabs samples presoaked in sterile peptone broth were used to swab the egg shell surface. The swab samples were inoculated into peptone broth (Merck, Germany) and incubated for $18 \mathrm{~h}$ at $37^{\circ} \mathrm{C}$ (12). Twenty-five grams of beef or chicken meat were homogenized and mixed with 250 $\mathrm{ml}$ of buffered peptone water (Merck, Germany). After incubation for $18 \mathrm{~h}$ at $37{ }^{\circ} \mathrm{C}$, $0.1 \mathrm{ml}$ of the pre-enriched cultures were inoculated into $10 \mathrm{ml}$ of selenite F-broth (Merck, Germany) (13). After incubation at 37 ${ }^{\circ} \mathrm{C}$ for $18 \mathrm{~h}$, the samples were subcultured on Salmonella-Shigella agar (Merck, Germany) and Xylose Lysine Deoxycholate agar (Biolife, USA). After incubation at $37^{\circ} \mathrm{C}$ for $24 \mathrm{~h}$, colonies with typical morphology of Salmonella were subjected to differential tests including MR-VP, TSI, SIM and Simon-citrate (Biolife, USA)(14).

Agglutination test was performed with Baharafshan kit (Tehran, Iran) to detect serogroups A-D based on presence of $\mathrm{O}$ and $\mathrm{H}$ 
antigens according to the manufacturer's guidelines.

The standard $S$. Typhimurium ATCC 14028 and the isolated strains were grown in Brain Heart Infusion (BHI) broth (Merck, Germany) and incubated at $37^{\circ} \mathrm{C}$ overnight. The bacteria were then subcultured on BHI agar. After overnight incubation at $37^{\circ} \mathrm{C}$, single colonies were collected and whole genomic DNA was extracted by the boiling method. The invA gene sequence was amplified by PCR using invA gene primers (forward: 5'GTGAAATTATCGCCACGTTCGGGCAA3', reverse: 5'CATCGCACCGTCAAAGGAACC-3')

(Sinaclon Iran) as described previously (15). The PCR conditions were as follows: initial denaturation at $95{ }^{\circ} \mathrm{C}$ for $5 \mathrm{~min}$, denaturation at $94{ }^{\circ} \mathrm{C}$ for one min, annealing at $61{ }^{\circ} \mathrm{C}$ for one min, 30 cycles of extension at $72{ }^{\circ} \mathrm{C}$ for one min and final extension at $72{ }^{\circ} \mathrm{C}$ for 10 min. The purified PCR products (Figure 1) were sequenced by the Sanger dideoxy method (Seqlab, Germany). The obtained sequences were confirmed by alignment for invA gene using the DNA Databank of Japan. A nucleotide BLAST search of the sequences against the National Center of Biotechnology Information (NCBI) nucleotide sequence database was performed. Using neighborjoining method, a phylogenetic tree with 1,000 bootstraps was constructed in MEGA7 (Molecular Evolutionary Genetic Analysis Software, version 7.1).

\section{RESULTS}

The Salmonella serovars isolated from different food sources in Isfahan are listed in table 1. The frequency of isolates in beef, chicken and egg samples was $9.7 \%, 8.5 \%$ and $8 \%$, respectively. Moreover, $S$. Ouakam and $S$. Enteritidis were the most prevalent isolates from chicken (22.5\%), while $S$. Newport was isolated only from beef.
Overall, 10 Salmonella serotypes were identified. In the NCBI's BLAST search, 9799\% sequence identities were observed with sequences of Salmonella serovars reported from other countries. The phylogenetic tree was constructed using 34 sequences of invA genes obtained in this study and 15 sequences from studies in the US, China, Switzerland, Egypt, United Kingdom, Taiwan, South Africa, Republic of Korea and Canada. Yersinia enterocolitica strain AF542975.1 was used as an outgroup.

In the phylogenic construct (Figure 2), our sequences for $S$. Newport isolated from beef were placed in the same cluster with already reported sequences from USA. All $S$. Typhimurium isolates were placed in four separate clusters. Sequences reported from Korea and China along with our sequence of $S$. Typhimurium SS4 were placed in one cluster. However, $S$. TyphimuriumSS1 (obtained from our study) was placed in another cluster along with sequences from the USA and Switzerland. S. Typhimurium SOA1 was placed in a cluster with previously reported sequences from Australia, the United Kingdom, Taiwan and the USA. Two of our sequences related to $S$. Typhimurium SS11 and $S$. Typhimurium SS22 along with a sequence from USA were placed in the fourth cluster. All $S$. enterica serovar Anatum sequences were placed in the same cluster, which were similar to another cluster containing sequences reported from the USA. Our $S$. Ouakum sequences were placed in two distant clusters that each was along with sequences reported from China or the USA. Our only $S$. Nitra sequence was placed in a single cluster along with a sequence reported from Canada. Salmonella enterica Egy reported from Egypt was placed in a separate cluster.

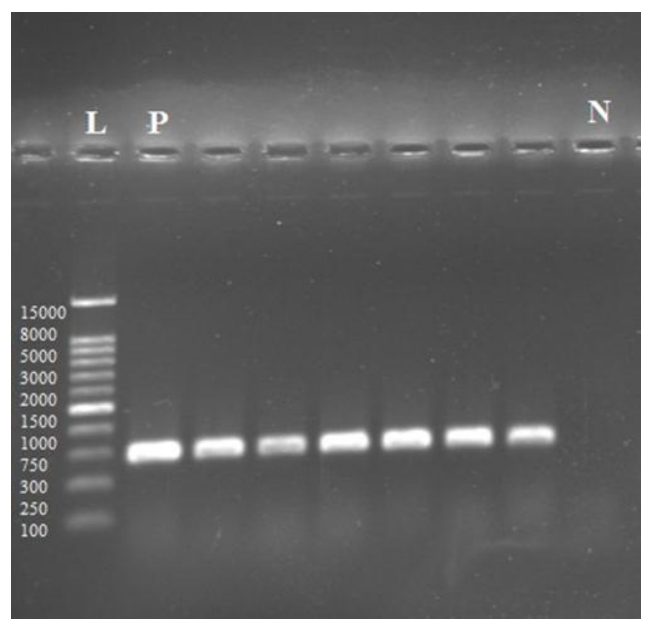

Figure 1. Electrophoresis results of invA gene PCR. L: 100bp DNA Ladder, P: positive control, $\mathrm{N}$ : negative control. 


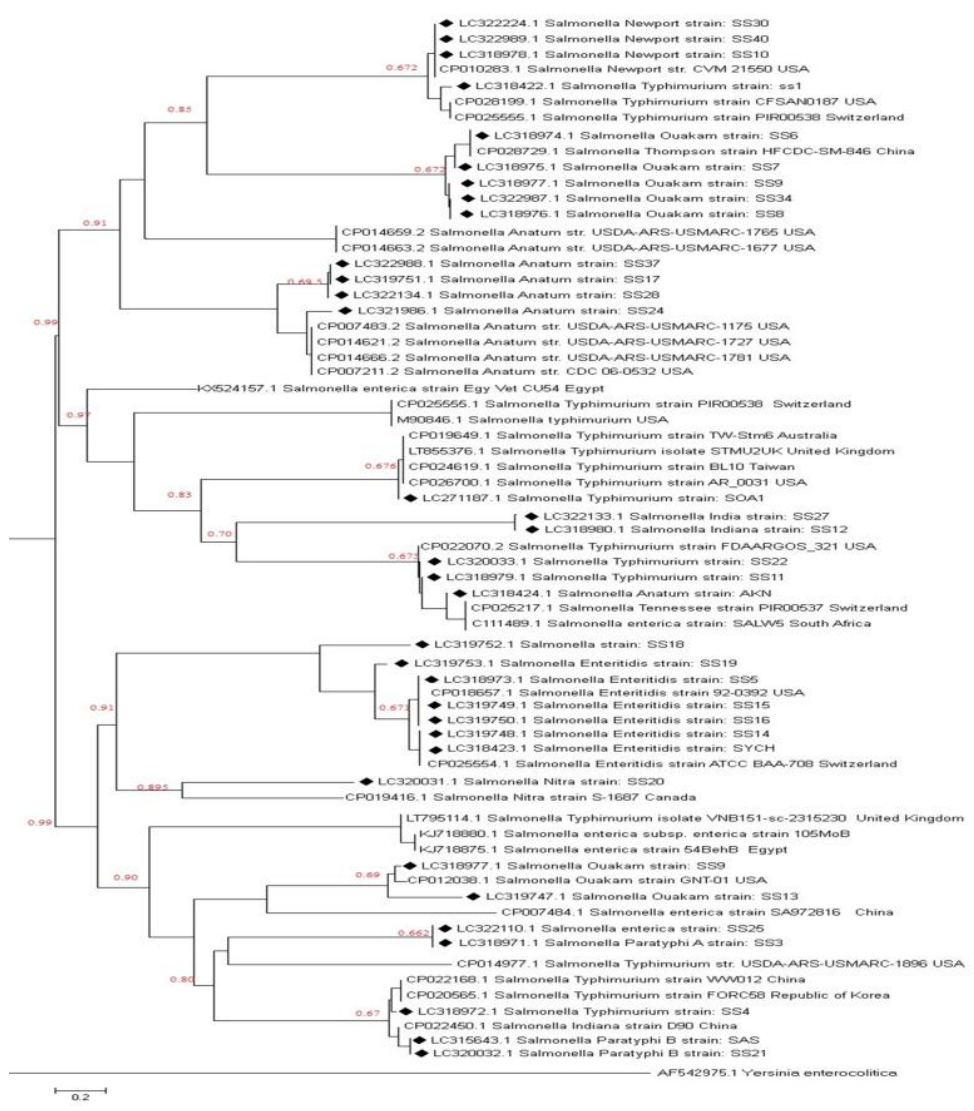

Figure 2. Phylogenetic tree of various Salmonella serovars from different parts of the world. • indicates Salmonella strains isolated in this study.

Table 1. Frequency of Salmonella serovars isolated from different sources

\begin{tabular}{|c|c|c|c|c|c|c|}
\hline Source & Number & $\%$ & Serovar/ & serogroup & Number of isolates & $\%$ \\
\hline \multirow[t]{13}{*}{ Broiler chicken } & 32 & 79.5 & $\begin{array}{l}\text { Salmonella Enteritidis } \\
\text { Salmonella Ouakam }\end{array}$ & $\mathrm{D}$ & $\begin{array}{l}7 \\
7\end{array}$ & 21.87 \\
\hline & & & Salmonella India & * & 5 & 21.87 \\
\hline & & & Salmonella Anatum & & 5 & \\
\hline & & & Salmonella Paratyphi B & * & 2 & 15.62 \\
\hline & & & Salmonella Paratyphi A & & 1 & \\
\hline & & & Salmonella Typhimurium & * & 3 & 15.62 \\
\hline & & & Salmonella Enterica & & 1 & \\
\hline & & & Salmonella Nitra & B & 1 & 6.25 \\
\hline & & & & A & & \\
\hline & & & & B & & 3.125 \\
\hline & & & & * & & 9.375 \\
\hline & & & & & & 3.125 \\
\hline & & & & & & 3.125 \\
\hline \multirow{3}{*}{ Egg } & 5 & 12.8 & Salmonella Typhimurium & B & 4 & 80 \\
\hline & & & Salmonella Ouakam & & 1 & \\
\hline & & & & * & & 20 \\
\hline Beef & 3 & 7.7 & Salmonella Newport & $\mathrm{C}$ & 3 & 100 \\
\hline
\end{tabular}




\section{DISCUSSION}

The contamination of foodstuff with Salmonella spp. and their transfer to humans are global health concerns (16). The marked increase in global consumption of poultry may subsequently increase the risk of poultryassociated foodborne diseases (17). In Canada, S. enterica serovar Hadar, Salmonella Kentucky and S. enterica serovar Heidelberg were the most prevalent serotypes in chicken meat (18), while in Vietnam, Salmonella Anatum followed by $S$. enterica serovar Infantis and $S$. enterica serovar Emek were the most prevalent isolates (19). Moreover, $S$. Typhimurium was reported as the most prevalent (10\%) serotype in Iraq (20). These findings show that various Salmonella serotypes are present in foodstuff from different parts of the world. In the present study, $8.5 \%$ of chicken meat samples were contaminated with Salmonella spp., mainly with $S$. Ouakam or $S$. Enteritidis. Previous studies in Poland (4) and the USA (18) also reported a high rate of $S$. Enteritidis and $S$. Ouakam contamination (21). In a study in Brazil, only $12 \%$ of the isolates were $S$. Enteritidis (22). In a study in Egypt on 450 cloacal, 400 chicken egg and 250 chicken meat samples, the highest rate of contamination ( $2 \%$ with $S$. Enteritidis) was related to chicken meat (23). The high rate of Salmonella contamination in chicken meat samples could be associated with breeding, transport, slaughtering and packaging stages. Due to the high risk of human infection, culling of the contaminated flocks and sophisticated sanitary procedures are recommended. Another source of infection with Salmonella spp. is contaminated eggs. The prevalence of egg contamination varies in different geographical locations. In the present study, $8 \%$ of the tested eggs were contaminated with Salmonella spp. [S. Typhimurium (80\%) and S. Ouakam (20\%)].

In India, the rate of egg contamination with $S$. Typhimurium (24) and $S$. Enteritidis (25) was reported to be $5 \%$ and $10 \%$, respectively. However, a study in South Korea found no Salmonella contamination among 135 chicken eggs (26). Egg shells can be contaminated with Salmonella spp. during laying by contact with stool or other contaminated eggs during collection (27). Indeed, implementing proper procedures to prevent contamination of eggs during these processes could reduce the risk of
Salmonella infections in humans.

$S$. enterica serovar Dublin, $S$. Enteritidis, $S$. Typhimurium and $S$. Newport are the most prevalent Salmonella spp. isolated from cows and calves $(28,29)$. In the present study, of 31 beef samples, three cases $(9.7 \%)$ were contaminated with $S$. Newport. In a study in Denmark on 2,985 retail pork and chicken meat samples, $S$. Newport was isolated only from two samples (30). In Mexico City, except for $S$. Typhimurium and $S$. Anatum, $14.7 \%$ of chicken, pork and beef ground meat were contaminated with $S$. Newport (31). Studies in Canada, England and China reported other Salmonella spp. including $S$. Enteritidis, $S$. enterica serovar Indiana, $S$. Heidelberg and $S$. Typhimurium as the major contaminants of beef, chicken meat and retail meats (32-34). Inconsistent with our study, the mentioned studies found no $S$. Newport contamination. The high rate of $S$. Newport contamination in our study might be due to the fact that we tested already suspected samples delivered to the veterinary laboratory.

Based on the results, $S$. Ouakum, $S$. Enteritidis and $S$. Typhimurium were the most prevalent serovars of Salmonella in the foodstuff samples from Isfahan during the study period.

Given the diversity of Salmonella species, morphological and biochemical tests cannot identify every species; hence, molecular techniques are employed for a more specific identification of these species. In this study, 40 sequences from the invA gene of Salmonella spp. isolated from different food sources were compared to previously reported sequences by phylogenetic analysis. This showed that $S$. Ouakam species circulating in the region shares has the same ancestor with the ones reported from the USA. This may be due to importation of animal food ingredients from the US, migration of wild birds (35), etc.

\section{CONCLUSION}

In this study, $S$. Typhimurium species is placed in different clusters along with sequences reported from different parts of the world, indicating that the serovars are circulating all over the world.

\section{ACKNOWLEDGMENTS}

This study was funded by the Department of Research and Graduate Studies of University of Isfahan, Iran. The authors would like to thank staff of the veterinary reference laboratory of Isfahan Province for their assistance in sample collection. 


\section{CONFLICT OF INTEREST}

The authors declare that there is no conflict of interest.

\section{REFERENCES}

1.Brenner F, Villar R, Angulo F, Tauxe R, Swaminathan B. Salmonella nomenclature. J Clin Microbiol. 2000; 38(7): 2465-7.

2.Rohrbach BW, Draughon FA, Davidson PM, Oliver SP. Prevalence of Listeria monocytogenes, Campylobacter jejuni, Yersinia enterocolitica, and Salmonella in bulk tank milk: risk factors and risk of human exposure. J food prot. 1992;55(2):93-7.

3.Wong CL, Sieo CC, Tan WS, Abdullah N, Hair-Bejo $\mathrm{M}$, Abu J, et al. Evaluation of a lytic bacteriophage, $\Phi$ st1, for biocontrol of Salmonella enterica serovar Typhimurium in chickens. Int J food microbiol. 2014; 172: 92-101.

4.Mąka Ł, Maćkiw E, Ścieżyńska H, Pawłowska K, Popowska M. Antimicrobial susceptibility of Salmonella strains isolated from retail meat products in Poland between 2008 and 2012. Food Control. 2014; 36: 199204.

5.Angulo FJ, Johnson KR, Tauxe RV, Cohen ML. Origins and consequences of antimicrobial-resistant nontyphoidal Salmonella: implications for the use of fluoroquinolones in food animals. Microbiol drug res. 2000; 6: 77-83.

6.Carramiñana JJ, Rota C, Agustin I, Herrera A. High prevalence of multiple resistance to antibiotics in Salmonella serovars isolated from a poultry slaughterhouse in Spain. Vet Microbiol. 2004; 104(1-2): 133-9.

7.Forbes BA, Sahm DF, Weissfeld AS. Study guide for Bailey \& Scott's diagnostic microbiology: Mosby USA; 2007.

8.Uzzau S, Brown DJ, Wallis T, Rubino S, Leori G, Bernard S, et al. Host adapted serotypes of Salmonella enterica. Epidemiol Infect. 2000; 125(2): 229-255.

9.Zhao S, White D, Friedman S, Glenn A, Blickenstaff $\mathrm{K}$, Ayers S, et al. Antimicrobial resistance in Salmonella enterica serovar Heidelberg isolates from retail meats, including poultry, from 2002 to 2006. Appl Environ Microb. 2008; 74(21): 6656-6662. DOI: 10.1128/AEM.01249-08.

10.Janda JM, Abbott SL. The enterobacteria. American Society for Microbiology, ASM. 2006.

11.Le Hello S, Hendriksen RS, Doublet B, Fisher I, Nielsen EM, Whichard JM, et al. International spread of an epidemic population of Salmonella enterica serotype Kentucky ST198 resistant to ciprofloxacin. J. Infect. Dis. 2011; 204: 675-684.

12.Loongyai W, Promphet K, Kangsukul N, Noppha R, Egg A. Detection of Salmonella in egg shell and egg content from different housing systems for laying hens. IJFSB. 2010; 4: 232-234.

13.Sahm DF, Weissfeld A, Trevino E. Baily and Scott's Diagnostic Microbiology. Mosby, St Louis. 2002.

14. Oliveira S, Rodenbusch C, Cé M, Rocha S, Canal C. Evaluation of selective and non-selective enrichment PCR procedures for Salmonella detection. Lett Appl Microbiol. 2003; 36(4): 217-221.
15.Rahn K, De Grandis S, Clarke R, McEwen S, Galan J, Ginocchio $\mathrm{C}$, et al. Amplification of an invA gene sequence of Salmonella typhimurium by polymerase chain reaction as a specific method of detection of Salmonella. Mol cell probes. 1992; 6: 271-279.

16.Sharma I, Das K. Detection of invA Gene in isolated Salmonella from marketed poultry meat by PCR assay. J Food Process Technol. 2016; 7: 122-127. DOI: 10.4172/2157-7110.1000564.

17.Van Kessel J, Karns J, Perdue M. Using a portable real-time PCR assay to detect Salmonella in raw milk. J Food Process Technol. 2016; 7: 122-127. DOI: 10.4172/2157-7110.1000564.

18.Bosilevac JM, Guerini MN, Kalchayanand N, Koohmaraie M. Prevalence and characterization of salmonellae in commercial ground beef in the United States. Appl Environ Microbiol. 2009; 75(7): $1892-$ 90000.

19.Thai TH, Hirai T, Lan NT, Yamaguchi R. Antibiotic resistance profiles of Salmonella serovars isolated from retail pork and chicken meat in North Vietnam. Int $\mathrm{J}$ Food Microbiol. 2012; 156(2): 147-51. doi: 10.1016/j.ijfoodmicro.2012.03.016

20.Saeed AA, Hasoon MF, Mohammed MH. Isolation and molecular identification of Salmonella typhimurium from chicken meat in Iraq. World Poultry Sci J. 2013; 3: 63-67.

21.Wu D, Alali W, Harrison M, Hofacre C. Prevalence of Salmonella in neck skin and bone of chickens. J food prot. 2014; 77: 1193-1197.

22.Paião F, Arisitides L, Murate L, Vilas-Bôas G, VilasBoas L, Shimokomaki M. Detection of Salmonella spp, Salmonella Enteritidis and Typhimurium in naturally infected broiler chickens by a multiplex PCR-based assay. Braz J Microbiol. 2013; 44(1): 37-41. doi: 10.1590/S1517-83822013005000002.

23.Al-Hazmi M, Al-Arfaj A, Mostafa A, Ihab M. Molecular Detection of Salmonella enteric Serovar Enteritidis in Chicken-Related Samples Collected from Egypt. Life Sci J. 2013; 10(3): 2645-2649.

24.Singh S, Yadav AS, Singh SM, Bharti P. Prevalence of Salmonella in chicken eggs collected from poultry farms and marketing channels and their antimicrobial resistance. Food Res Int. 2010; 43: 2027-2030.

25.Samanta I, Joardar S, Das P, Sar T, Bandyopadhyay $\mathrm{S}$, Dutta $\mathrm{T}$, et al. Prevalence and antibiotic resistance profiles of Salmonella serotypes isolated from backyard poultry flocks in West Bengal, India. JAPR. 2014; 23(3): 536-545.

26.Chang YH. Prevalence of Salmonella spp. in poultry broilers and shell eggs in Korea. J Food Prot. 2000; 63(5): 655-658.

27.Little CL, Walsh S, Hucklesby L, Surman-Lee S, Pathak K, Hall Y, et al. Salmonella contamination in non-UK produced shell eggs on retail sale in some regions of England. Euro Surveill. 2006; 11(11): E061123.4.

28.Genovese K, Jung Y, McReynolds J, Anderson R, Nisbet D. Antimicrobial resistance and serotype prevalence of Salmonella isolated from dairy cattle in the southwestern United States. Microb drug res. 2004; 10(1): 51-56. DOI:10.1089/107662904323047808. 
29.Sorensen O, McFall M, Manninen K. Prevalence of Salmonella in dairy herds in Alberta. Can Vet J. 2003; 44(3): 230-235.

30.Skov MN, Andersen JS, Aabo S, Ethelberg S, Aarestrup FM, Sørensen AH, et al. Antimicrobial drug resistance of Salmonella isolates from meat and humans, Denmark. Emerg. 2007; 13(4): 638-643. doi: 10.3201/eid1304.060748.

31.Villalpando-Guzmán S, Vázquez-Quiñones CR, Natividad-Bonifacio I, Quiñones-Ramírez EI, VázquezSalinas C. Prevalence ofSalmonella in Chicken, Beef and Pork Meat in Mexico City. AJMR. 2016; 4: 5-11.

32.Aslam M, Checkley S, Avery B, Chalmers G, Bohaychuk V, Gensler G, et al. Phenotypic and genetic characterization of antimicrobial resistance in Salmonella serovars isolated from retail meats in Alberta, Canada. Food microbiol. 2012; 32(1): 110-117.
33.Little C, Richardson J, Owen R, De Pinna E, Threlfall E. Campylobacter and Salmonella in raw red meats in the United Kingdom: prevalence, characterization and antimicrobial resistance pattern, 2003-2005. Food Microbiol. 2008; 25(3): 538-43. doi: 10.1016/j.fm.2008.01.001.

34.Yang B, Qu D, Zhang X, Shen J, Cui S, Shi Y, et al. Prevalence and characterization of Salmonella serovars in retail meats of marketplace in Shaanxi, China. Int $\mathrm{J}$ Food Microbiol. 2010; 141(1-2): 63-72. doi: 10.1016/j.ijfoodmicro.2010.04.015.

35.Afema JA, Sischo WM. Salmonella in wild birds utilizing protected and human impacted habitats, Uganda. EcoHealth. 2016; 13(3): 558-569.

\section{How to Cite:}

This paper should be cited as: Sabzali S,. Bouzari M. [Phylogenic Relationship of Salmonella Serovars Isolated from Different Foodstuffs in Isfahan]. mljgoums. 2020; 14(4): 20-26. DOI:10.29252/mlj.14.4.20 